\title{
Pore microstructure variation in gradient consolidation of Pearl River Delta saturated clay
}

\author{
ZHANG Peng ${ }^{1, a}$, LIU Zhiqing ${ }^{2, b}$, SONG Jing ${ }^{2, c^{*}}$ \\ ${ }^{1}$ CCCC-FHDI Engineering co., Ltd., Guangzhou 510230, China \\ ${ }^{2}$ School of Earth Sciences and Geological Engineering, Sun yat-sen University, Guangzhou \\ 510275, China \\ ahp20120619@126.com, ${ }^{\mathrm{b}}$ easky@126.com, ${ }^{\mathrm{c}}$ 164257487@qq.com \\ ${ }^{*}$ Corresponding author
}

\begin{abstract}
Keywords: Pore microstructure, Gradient consolidation, Saturated clay, SEM, Seepage paths Abstract: The microstructure porosities and pore size distribution of the clayey soil in the Pearl River Delta were studied by techniques of Scanning Electron Microscopy (SEM) and pressure gradient method. It was found that small pores were increased with increasing of the loading of clay samples. On the other hand, large pores with diameter of over $4 \mu \mathrm{m}$ were obviously decreased with increasing the loadings because of the squeeze effect to cause the large pores to be broken into smaller ones. The loading amount was investigated based on the stress change to improve the efficiency of saturated clayed soil foundation treatment. The effect of stress distribution on mechanical properties in the consolidation process was also investigated through the rate of anisotropy characteristics in the same full of saturated soft clay. The maximum principal stress and pore size with short axis angle were reduced.
\end{abstract}

\section{Introduction}

Pore shrinkage in the consolidation process would be accordingly changed to further affect the soil mechanic behavior which related to the type and intensity of pressure[1]. It is well known that drainage paths are primarily controlled by pressure, and clay-rich soils contain a network of pores on different scales. The network system most likely determines the consolidation mechanism and drainage behavior. Furthermore, pore space geometry is potentially related to the mechanical properties of consolidation[2]. And the effect of adaptive consolidation, a comprehensive consolidation mechanism and processes was postulated[3]. So the aim of this research could be focused on the process of clay migration controlled by the pressure. And the objective of this research work is clay-rich soil consolidation to apply in soft soil reclamation engineering.

The basic treatment of Pearl River Delta clay tends to use drain consolidation method. The application of alternative technique of gradient pressure could be demonstrated by the measurement of distribution and direction of clay in this progressive consolidation method[4]. In the process of consolidation, small-scale data of pore microstructure gotten by photos in laboratories would be obtained in the regulation of drain consolidation by vacuum preloading method in microstructure compaction of Pearl River Delta clay.

However, clay-rich soil consolidation has been studied by various laboratory instruments through changing the vacuum preloading degree with loadings of water and soil. The corresponding drain consolidation in the vicinity of the drainpipe exhibits an improved impact on the fine clay particles with high concentration[5]. Based on the relationship between vacuum pressure gradient of sensitive clays and grain size distribution, a new technique, the pressure gradient method, was first proposed and used by Professor Wang in 2009 to consolidate soft clay[6]. The principle of the method is that clayey soil would also be altered with temperature change of environment. 


\section{Experimental}

Pearl River Delta clay, as a special kind of soft soil formed under shallow paralic environment, is distributed in the third alternating facies in the South China[7]. The site to collect Pearl River Delta clay is located $20 \mathrm{~km}$ south of Guangzhou, China. Based on reclaimation engineering, the materials were most disturbed by dredgering. Distilled water was added to raw clay-rich soil until the weight ratio of water to soil was 1.2:1.

In order to consolidate soft soil, it is usually constructed by vacuum preloading method which is the common geotechnique skill with vacuum degree at least $-85 \mathrm{kPa}$. In this circumstance, soft soil should be sealed by plastic membrane, and then should be subjected the pore water to a pumping force. However, clay-rich soil is not consolidated well due to fine particles migrating. Pumping force may be influenced surface of clay with different loadings of $50 \mathrm{kpa}, 100 \mathrm{kpa}$, and $200 \mathrm{kpa}(100 \mathrm{kPa}$ vacuum and $100 \mathrm{kPa}$ plus surface load), which was collected and used to measure the variation microstructure.

The samples for SEM were collected twice in the progress of experiments which is convenient to extract samples in both vertical and horizontal approaches. They were quenched by liquid nitrogen with water content of more than $40 \%$ for about $10 \mathrm{~min}$ in vacuum of $-90 \mathrm{kPa}$ at $-50^{\circ} \mathrm{C}$. Then soil chips were spray coated by gold to improve sample electrical conduction for SEM analysis[8]. The observation information of SEM images is discribed by Photoshop software and image test software for qualitative and quantitative analyses as Fig.1. Each sample is not obtained identical binary because pores and particles are generally in dark gray color compared with background. It is difficult to directly determine the microstructure differences.
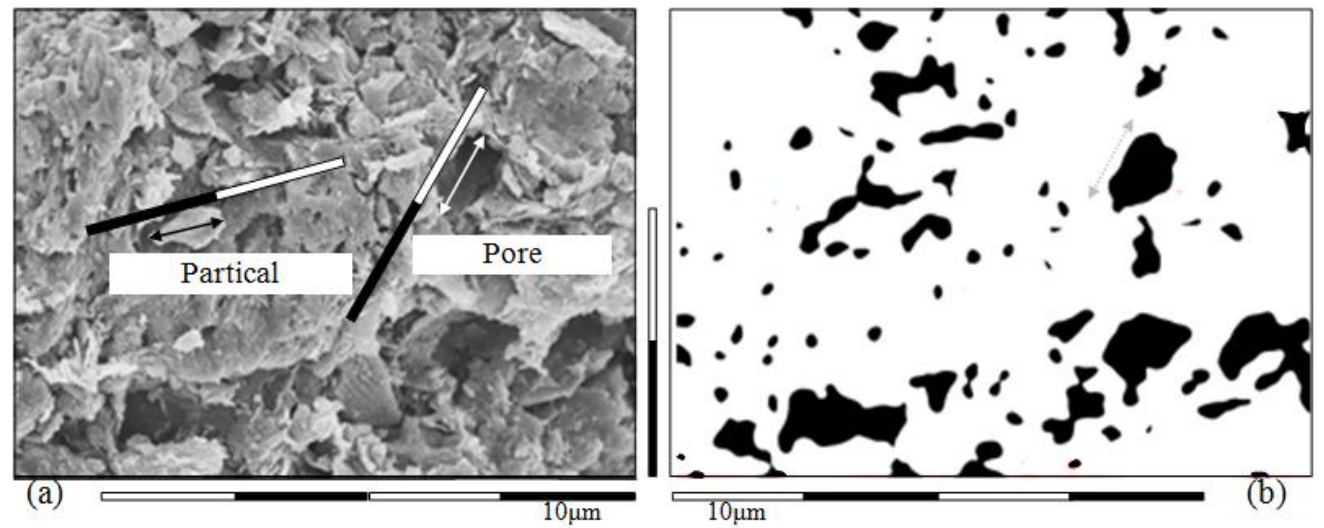

Fig.1. (a) Images of particles and pores, (b) pore image processing

\section{Microstructural composition of clay}

6 types of images with magnification of 2000 times were collected to study the characteristic of microstructures in horizontal and vertical directions. The results were listed in Table 1. Porosity of samples was calculated by Scion Image with data of particle arrangement. In the condition of loose particle arrangement, the porosity of the samples was 0.4764 . The porosity of the samples in closely packed condition was 0.2595 . Base on the relationship between the porosity and equivalent diameter, the equivalent aperture was estimated as 0.368 by using the following equation.

Table 1. Summary of the characteristics sample microstructure

\begin{tabular}{cccc}
\hline Number & Type & $\mathrm{H}($ Horizontal profile) & V (Vertical profile) \\
\hline 1 & $50 \mathrm{kPa}$ vacuum & $1 \mathrm{H} 1,1 \mathrm{H} 2,1 \mathrm{H} 3,1 \mathrm{H} 4$ & $1 \mathrm{~V} 1,1 \mathrm{~V} 2,1 \mathrm{~V} 3,1 \mathrm{~V} 4$ \\
2 & $100 \mathrm{kPa}$ vacuum & $2 \mathrm{H} 1,2 \mathrm{H} 2,2 \mathrm{H} 3,2 \mathrm{H} 4$ & $2 \mathrm{~V} 1,2 \mathrm{~V} 2,2 \mathrm{~V} 3,2 \mathrm{~V} 4$ \\
3 & $\begin{array}{c}100 \mathrm{kPa} \text { vacuum } \\
\text { and 100kPa overburden }\end{array}$ & $3 \mathrm{H} 1,3 \mathrm{H} 2,3 \mathrm{H} 3,3 \mathrm{H} 4$ & $3 \mathrm{~V} 1,3 \mathrm{~V} 2,3 \mathrm{~V} 3,3 \mathrm{~V} 4$ \\
& & & \\
\hline
\end{tabular}


The images of the samples with pore structure are shown in Fig.2. There are four groups of pores based on the microstructure pore characteristics in different pressure. The microstructure pores with an equivalent diameter of over $4 \mu \mathrm{m}$ were considered as large pore group. And they with an equivalent pore diameter of $0.4 \sim 4 \mu \mathrm{m}$ were considerd as medium. In addition, the equivalent diameter of 0.04 0.4 $\mu \mathrm{m}$ were considered as small. Then the pores with the equivalent diameter of less than 0.04 $\mu \mathrm{m}$ were considered as micro pore group. The micropore group was gradually decreased, while the small pore group was increased.
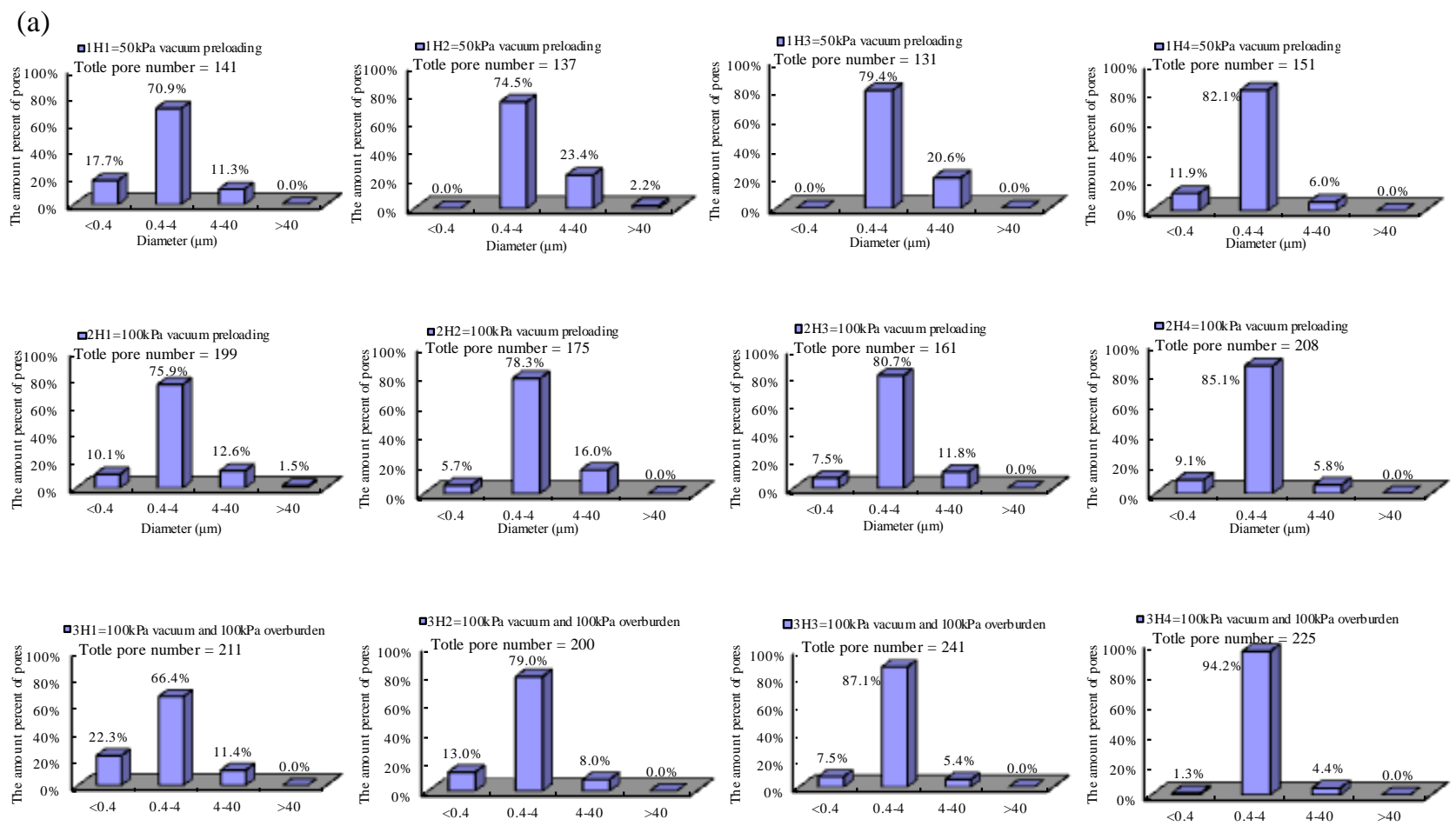

(b)
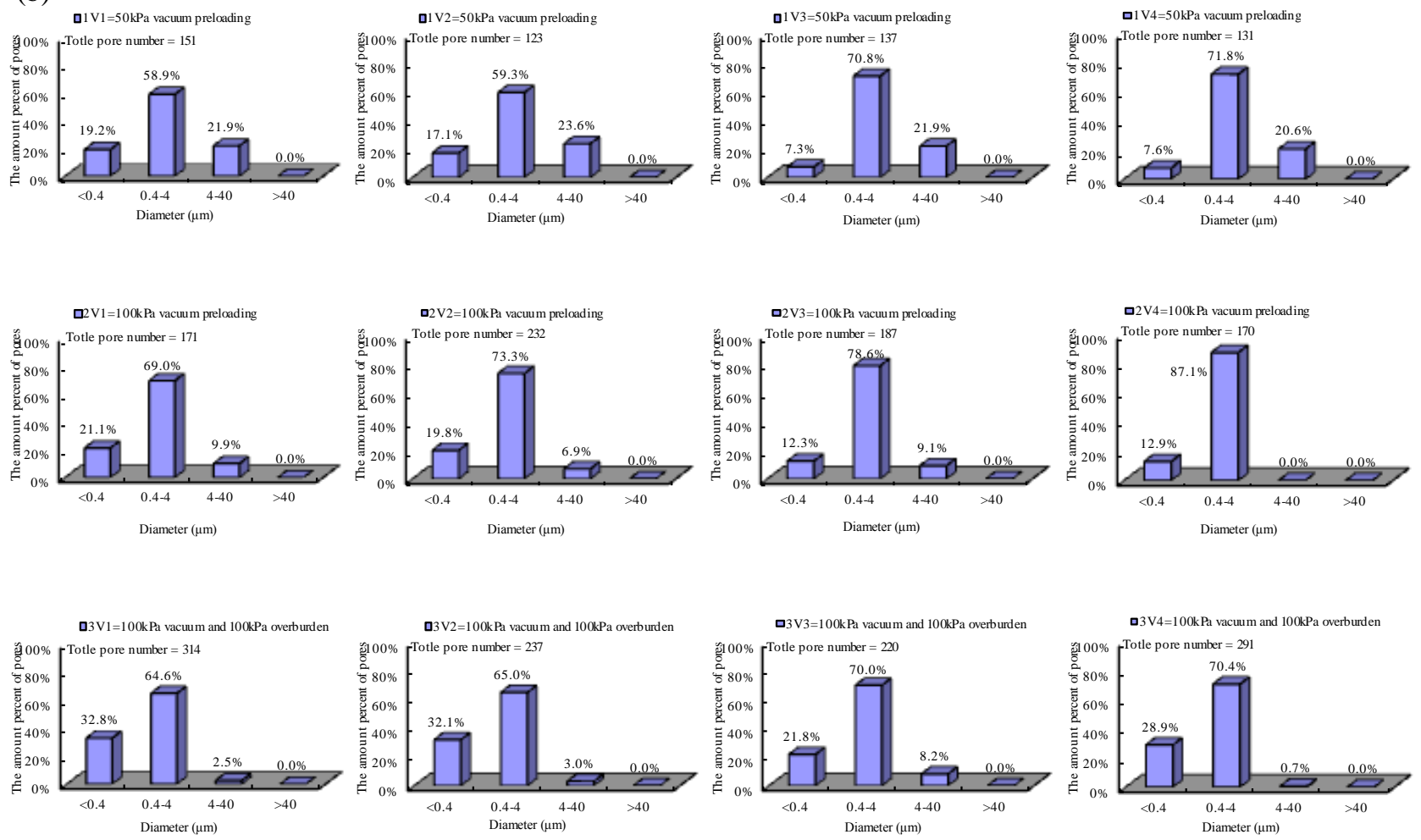

Fig.2 Pore characteristics of the horizontal (a) and vertical (b) profiles at each stage 
At the same time, two different types of pores with horizontal and vertical profile characteristics at each stage can be seen in Fig.3, in which the calculated pores at three pressure gradient stages were also shown. It was found that the small pore group was increased with increasing loading. However, the big large pore groups whose average diameter was bigger than $4 \mu \mathrm{m}$ were significantly decreased obviously. This is because the large pores would be broken out to smaller pores under squeezed condition not only because of reducing size of the large pore but also structure squeezed and broke out many smaller pores.

The total area of structure units and pores was estimated from the SEM images, as shown in Fig. 3. The ratio of pore area to structure unit area indicated that, in the same image area, the percentage of solid clay was relatively high in samples. The smaller pores formed from the large pore group exhibited the obvious direction. It indicated that vacuum combined overburden preloading affected porosity more seriously than the horizontal direction.
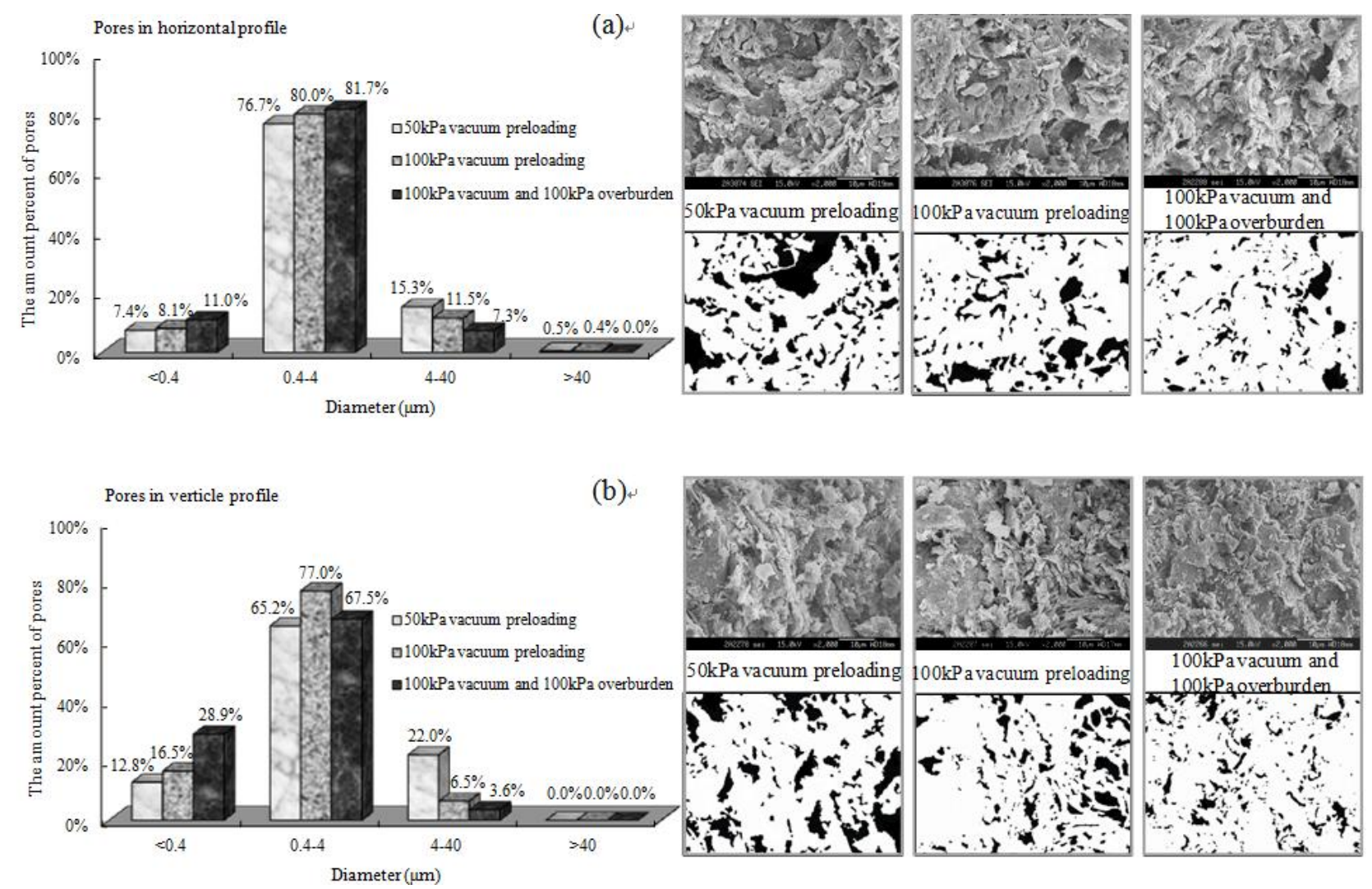

Fig.3 Pore distribution of clay samples in horizontal (a) and vertical (b) profiles

Orientation angle of pores would be rotated along long-axis direction from $0^{\circ}$ to $180^{\circ}$. The directional frequency can be calculated by the following equation (1) through the amount of pores.

$$
F(\alpha)=\frac{n_{\alpha}}{n}
$$

where $F(\alpha)$ is the directional frequency, $n_{\alpha}$ is the interval number of pores along the direction of $\alpha^{\circ}$, $\mathrm{n}$ is the total number of pores. Here $\alpha$ is equal to $20^{\circ}$.

The directional frequency distribution was analyzed for two types of profiles of horizontal direction and vertical direction, as shown in Fig.4. However, in vertical section, the directional characteristic of pore distribution was observed clearly. Based on these orientation angles, the rate of anisotropy characteristics reflected the stress distribution in solidification process. Especially, the maximum principal stress direction and pores with short axis angle were relatively smaller. 

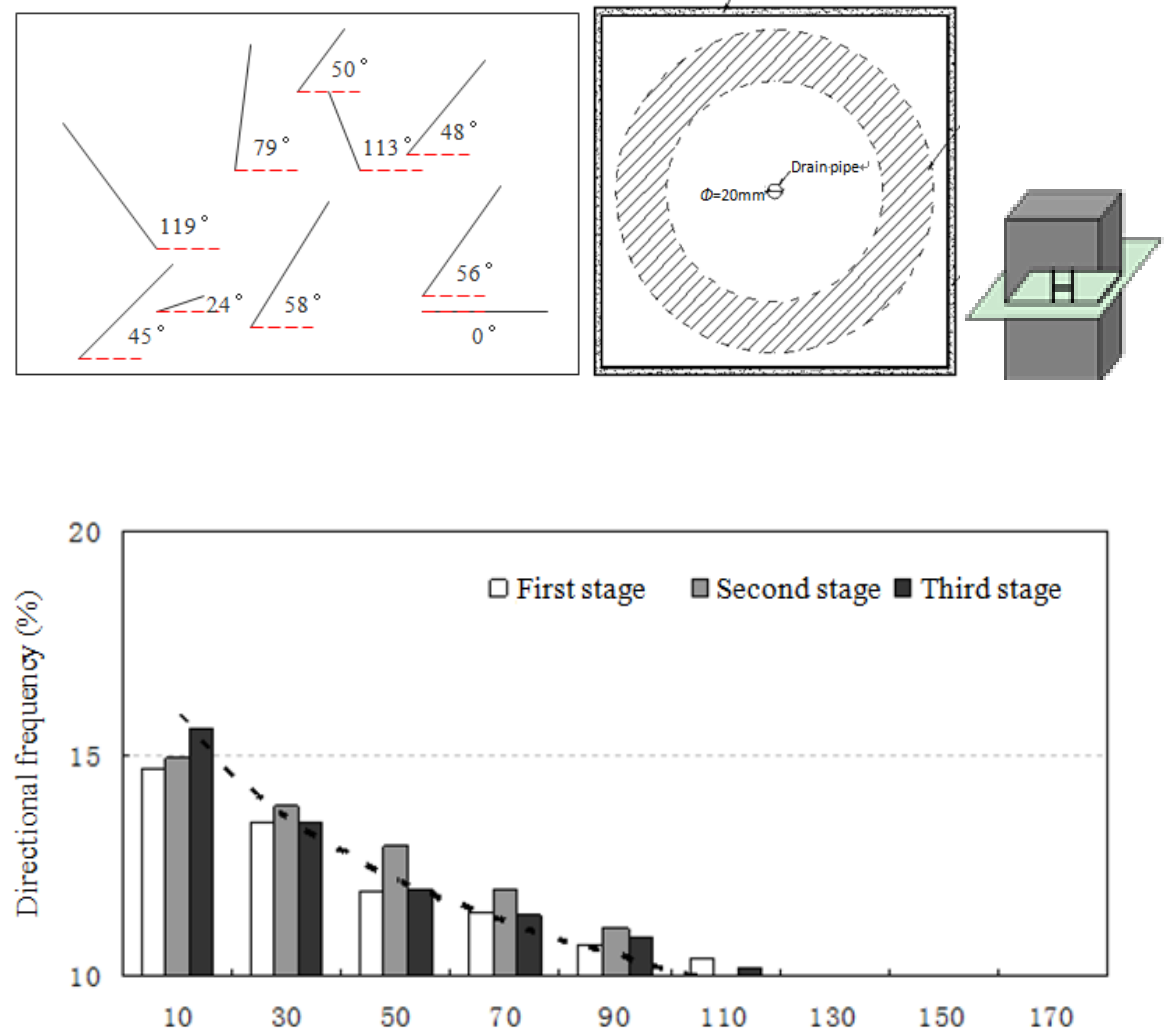

(a) Long-axis direction of pore distribution in the horizontal profile (median interval range $\pm 10^{\circ}$ )

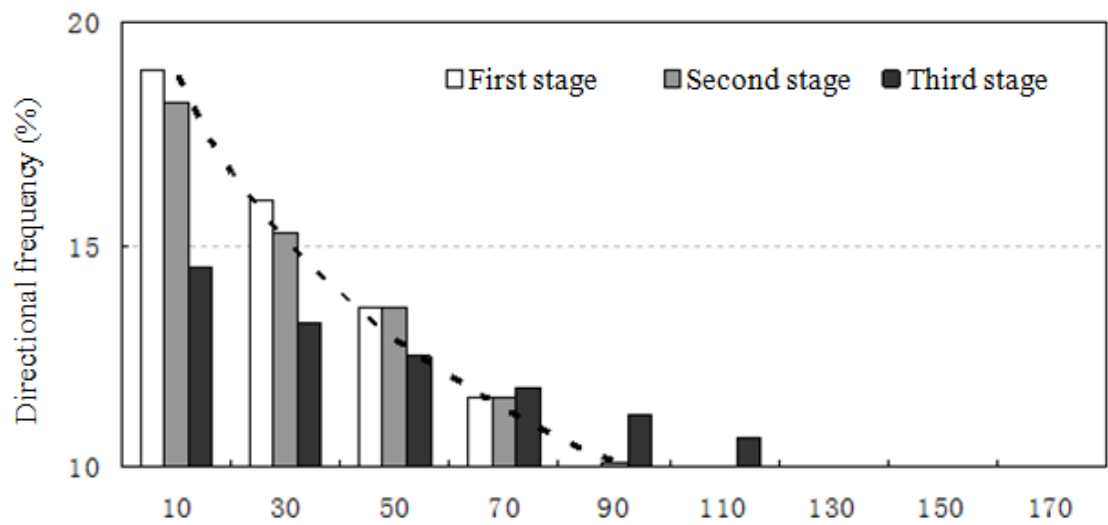

(b) Long-axis direction of pore distribution in the vertical profile (median interval range $\pm 10^{\circ}$ )

Fig. 4. Orientation angle along the long-axis direction of pores in horizontal (a) and vertical (b) profiles

\section{Discussion}

Preloading is an effective reinforcement method to study the pore structure of saturated soft clay. However, there are many factors, such as soil thickness, void ratio, and external load, affecting the drainage consolidation. Through complex calculation, the degree of drainage consolidation could be given. By comparing the difference of porosity between horizontal and vertical profile, it was found that the porosity of the vertical section is more directional with larger pore diameter. This is because the vertical plane of pores was the main channels for soil moisture discharge in the consolidation process. Thus, it can be concluded that the vertical large pores were resulted from water flow.

Quantitative analysis was carried out through pore parameter, which can be restored as the original image characteristics. SEM images showed the pore shape with irregular circle. It indicated that the small pore group was increased with increasing pressure, and the number of horizontal section and pores was increased as well. Void ratio was correspondingly gradually decreased. And the horizontal 
section void ratio was dropped rapidly, and the reduction rate of the porosity of the vertical section was slightly slower than the decline because of the formation of vertical flow channeling. Under the seepage force, horizontal direction was the main drainage channel of soil body with more pores.

\section{Conclusions and perspectives}

This study focused on the pore distribution in microstructure, grain size analysis, and false interference. The distributions of saturated soft clay seepage channels status and arrangement characteristics were obtained by testing soil pore structure of horizontal section and vertical section. For the horizontal section, the round-like pores were abundant, but the direction was not obvious. For the vertical section, the pores were relatively flat with low abundance and the obvious direction.

The large pores in the horizontal section were decreased with increasing pressure gradient. The chaotic degree was low. It indicated that the isotropic characteristic was gradually appeared. However, with increasing pressure gradient, the small pores in the vertical section were significantly increased, and the chaotic degree was gradually reduced. The microstructure with anisotropic characteristics would be improved by fully vibrating the saturated soft clay. The stress change in the consolidation process of the saturated soft clay is important in engineering. The loading would be performed step by step based on the stress change to improve the efficiency of saturated soft clay foundation treatment.

\section{Acknowledgements}

This work was financially supported by Natural Science Foundation of Guangdong Province China (S2012040007331), National Natural Science Foundation of China (41402239), the Foundation for Distinguished Young Talents in Higher Education of Guangdong, China (2012LYM_0007), and the Foundation for Young Teacher by the Ministry of Sun Yat-sen University (13lgpy63).

\section{References}

[1] Pillai, R.J., Robinson, R.G., Boominathan, A.. Effect of Microfabric on Undrained Static and Cyclic Behavior of Kaolin Clay. Journal of Geotechnical and Geoenvironmental Engineering. Vol.137(4), (2011), p.421-429.

[2] Cui, Y.J., Nguyen, X.P., Tang, A.M.. An insight into the unloading/reloading loops on the compression curve of natural stiff clays. Applied Clay Science. Vol.83-84, (2013), p.343-348.

[3] Ma, B.N., Muhunthan, B., Xie, X.Y.. Stress history effects on 1-D consolidation of soft soils: a rheological model. International Journal for Numerical and Analytical Methods in Geomechanics. Vol.37(16), (2013), p.2671-2689.

[4] Horpibulsuk, S., Miura, N., Koga, H., Nagaraj, T.S.. Analysis and strength development in deep mixing: a field study. Ground Improvement. Vol.8(2), (2004), p.59-68.

[5] Rao, S.M., Thyagaraj, T.. Swell-compression behaviour of compacted clays under chemical gradients. Canadian Geotechnical Journal. Vol.44(5), (2007), p.520-532.

[6] Song, J.. Laboratory simulation test and PFC3D numerical analysis of high clay dredger fill in the consolidation process of step-vacuum-preloading, $\mathrm{PhD}$ dissertation, Jilin University, China, (2011).

[7] Yim, W.W., Huang G., Radtke U.. Sratigraphy and optically stimulated luminescence dating of subaerially exposed Quaternary deposits from two shallow bays in Hong Kong, China Quaternary. International. Vol.183, (2008), p.23-39.

[8] Musso, G., Romero, E., Della Vecchia, G.. Double-structure effects on the chemo-hydromechanical behaviour of a compacted active clay. Geotechnique. Vol.63(3), (2013), p.206-220. 